\title{
The relationship between family-to-work conflict of employee and co-workers' turnover intention
}

\author{
Tavakol Sharafi" and Zohreh dehdashti shahrokh
}

Department of Management \& Accounting, Allameh Tabataba'i University, Tehran, Iran

\begin{tabular}{l}
\hline A R T I C L E I N F O \\
\hline Article history: \\
Received July 25, 2011 \\
Accepted 8 October 2011 \\
Available online \\
12 October 2011 \\
\hline Keywords: \\
Work-family conflict \\
Employee engagement \\
Turnover intention
\end{tabular}

Turnover intention \begin{abstract}
A B S T R A C T
Previous studies have convincingly shown that employees' family lives can affect their work outcomes. We investigate whether family-to-work conflict (FWC) experienced by the employee also affects the turnover intention of a co-worker. We predict that the employee's FWC has an effect on the co-worker's turnover intention through the crossover of positive and negative work attitudes. Using a sample of 154 co-worker dyads, we found that the employee FWC was positively related to co-worker turnover intention through the crossover of (reduced) work engagement. Results show that family matters at work, affecting employee. In addition, employee's job engagement was positively related to his (her) co-worker job engagement and it was negatively related co-worker turnover intention and employee's FWC was not positively related to co-worker turnover intention trough the crossover of (reduced) feelings of engagement.
\end{abstract}

\section{Introduction}

Work-family conflict (WFC), that is, the experience of incompatibilities between work and non-work roles, has become a concern for employees, companies, and scientists. Researchers interested in the work-family conflict have devoted significant attempts to investigate these issues. There are many evidences, which indicate the work domain can substantially influence different aspects of the family domain such as quality of family life, marital tension, marital functioning, and anxiety and mood at home (Eby et al., 2005). One of the most important issues, which could significantly influence managing family, is the possible conflicts. Work-family conflict is believed to negatively associated with family satisfaction, job satisfaction, depression, anxiety disorders, mood disorders, physical health complaints, hypertension, and alcohol consumption (Matthewsa et al., 2011). It is a commonly held belief, especially among banking industry, that work and family are two independent life domains.

\footnotetext{
* Corresponding author. Tel: +0989395886550.

E-mail addresses: t.sharafi1986@gmail.com (T. Sharafi) 
While knowledge on the effects of family-to-work interference for the employee's work outcomes accumulates, the consequences for co-workers' work outcomes have hardly been studied yet. Today's work is often organized in departments, whereby co-workers depend on each other for the completion of their tasks. Department entails frequent interaction between coworkers, such as advising or motivating each other. In work settings where co-workers closely cooperate, it is possible that one coworker is impeded in doing his or her job when the family life of the other co-worker interferes at work.

The question addressed in this study therefore is whether the work-family conflict (WFC) experienced by the employee affects a co-worker's turnover intention. Secondly, we examine in more detail why employee WFC affects turnover intention. The family-work literature suggests that family matters may conflict with work due to a shortage in time and energy, resulting in feelings of burnout at work (ten Brummelhuis et al., 2010). Furthermore, when family life conflicts with work, the employee is distracted at work, which may result in reduced work engagement. Feelings of reduced engagement (vigor, dedication and absorption) at work may, in turn, cross over between co-workers (Bakker et al., 2009). In the current study, we examine in detail whether such crossover effects occur between dyads of co-workers. More specifically, we investigate whether any effects of employee WFC on a co-worker's turnover intention are due to the crossover of reduced engagement.

\section{Theoretical framework}

\subsection{Work-family conflict}

Work-family conflict is "a form of inter role conflict in which the role pressures from the work and family domains are mutually incompatible in some respect", such that participation in one domain becomes more difficult due to the demands of participation in the other domain and vice versa (van Daalen et al., 2006). Work-family conflict is considered to be bi-directional i.e., work can interfere with family (work-to-family conflict; WFC) and family can interfere with work (family-to-work conflict; FWC).
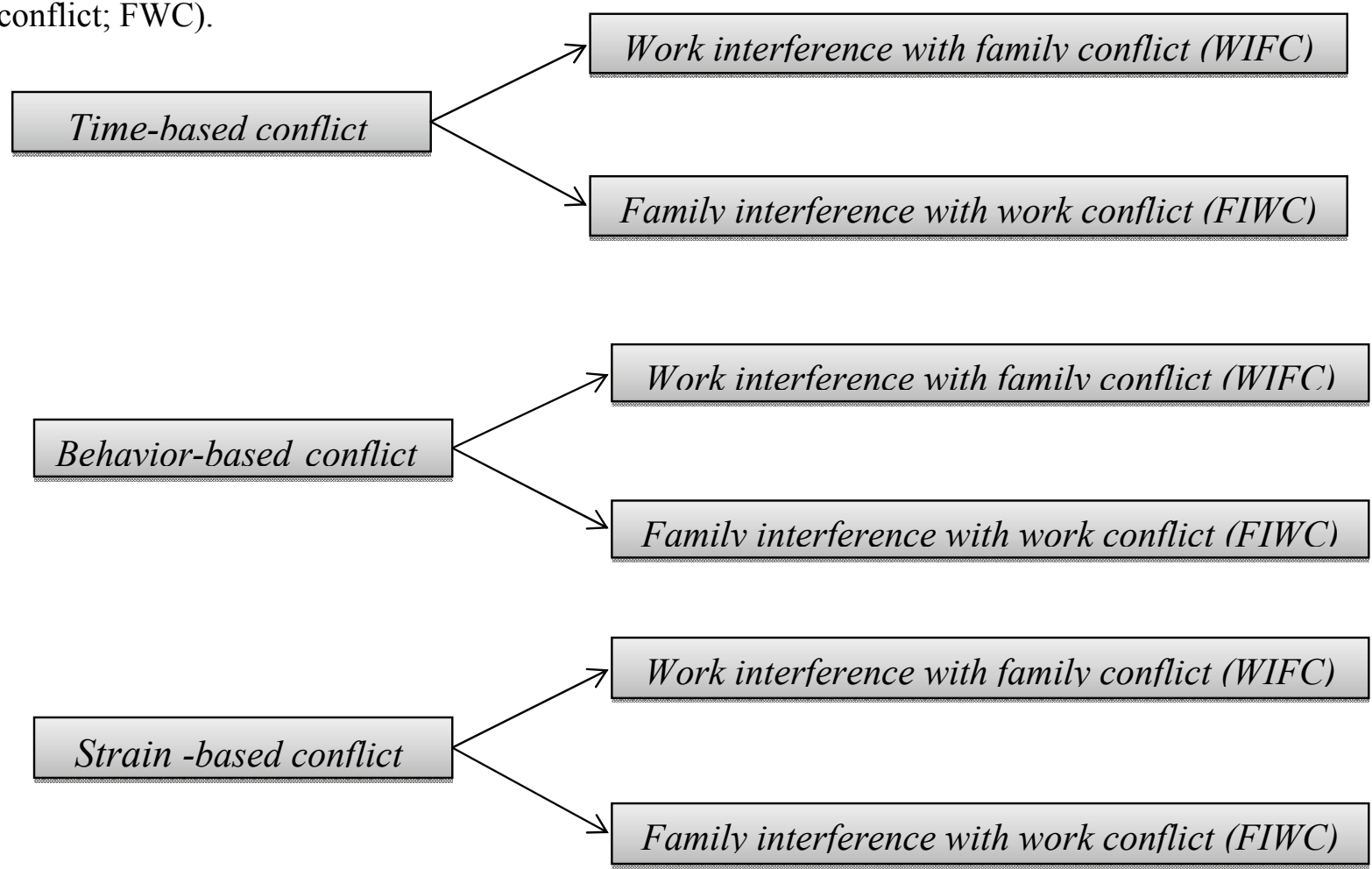

Fig. 1. Two directions of WFC 
As work-family conflict originates from various conditions, different forms of conflict are distinguished. Most researchers agreed that the general demands of including behavior, time devoted to, and strain produced by a given role are domain elements of the work-family conflict. Greenhaus and Beutell (1985) identified three forms of WFC, namely time-based WFC, strain-based WFC and behavior-based WFC (Liu \& Low, 2011).

Time-based conflict occurs when time spent on activities in one role impedes the fulfillment of responsibilities in another role. Behavior-based conflict occurs when behavior in one role cannot be adjusted to be compatible with behavior patterns in another role. The third form of WFC identified by Greenhaus and Beutell (1982) is strain-based conflict. This form of conflict occurs when pressures from one role interferes with fulfilling the requirements of another role (van Daalen et al., 2006). Traditionally, researchers have measured WFC uni-directionally where the conflict occurred when work interfered with family. However, definitions of WFC explicitly portray a bi-directional conceptualization to this phenomenon argued that each of the three forms of WFC has two directions (Liu \& Low, 2009). Fig. 1 shows details of different conflicts relationships.

\subsection{Employee engagement}

Work engagement has received increasing research attention over the past ten years, reflecting this emphasis. The concept of engagement can be traced back to Kahn (1990). He defines personal engagement as "the harnessing of organization members' selves to their work roles" and he adds, "in engagement, people employ and express themselves physically, cognitively, and emotionally during role performances". Personal disengagement is defined as "the uncoupling of selves from work roles" and "in disengagement, people withdraw and defend themselves physically, cognitively, or emotionally during role performances". When workers are engaged, they become physically involved in their tasks, cognitively alert, and emphatically connected to others. However, disengaged employees become physically uninvolved in tasks, cognitively unvigilant, and emotionally disconnected from others (Hyun et al., 2009). Engaged workers are energetic, are positively connected to their work and feel they are doing their jobs effectively. It is a persistent and broad affective-cognitive state (Burke \& El-Kot, 2010). Schaufeli et al. (2002), view it as a positive, fulfilling work-related state of mind that is characterized by vigor, dedication, and absorption. Vigor is characterized by high levels of energy, the willingness to invest energy in one's work and persistence in difficult times; dedication is characterized by high levels of work involvement and feelings of pride and challenge from one's work; and absorption is characterized by deep concentration in one's work the sense that time passes quickly and one is reluctant to leave their work. Others have defined work engagement in slightly different but generally consistent ways (Schaufeli \& Bakker, 2004). Kahn (1990) provided a conceptual basis for job engagement, but did not develop an operational definition. Maslach and Leiter (1997) expanded Kahn's (1990) conceptual work. They argued that job engagement is situated at the opposite end of the continuum of job burnout, characterized by energy (rather than exhaustion), involvement (rather than cynicism), and a sense of efficacy (rather than reduced professional efficacy) (Hyun et al., 2009).

\subsection{Turnover intention}

For the sake of clarity, turnover intention as presently defined is an employee's inclination to leave his or her organization. Actual turnover has been found to be very likely the result of intentions to withdraw (Harrison et al., 2006). Turnover intention is "a conscious and deliberate willfulness to leave the organization". Scholars define turnover intention as "individuals' own estimated probability (subjective) that they are permanently leaving the organization at some point in the near future" (Liu \& Low, 2011). Turnover intention as presently defined is an employee's inclination to leave his or her organization refers to an employee's tendency to stop being an organizational member (Lacity et al., 2008). Farkas and Tetrick (1989) insist that intention to leave the organization separates 
organizational commitment from decision to quit. In fact, turnover intention is the direct precursor of turnover behavior and reflects a combination of withdrawal related attitudes (Farkas \& Tetrick, 1989). Although researchers want to ideally understand turnover behavior, in reality, it is often difficult to empirically examine the behavior. Instead, researchers more typically survey current employees and ask them their turnover intentions. Turnover intentions are reliable predictors of turnover behaviors. Substantial empirical evidence supports the theory that attitude affects behavior more than behavior affects attitude (Lacity et al., 2008). Based on those definitions, we define turnover intention as the desire of employees to intentionally make a decision to leave the current organization permanently in the future. Turnover intention is one of the antecedents of actual turnover. Investigating the antecedents of turnover intention has become a key driver of turnover research. Previous scholars have identified a number of antecedents of turnover intention. These include dissatisfaction with jobs, organizational commitment, job embeddedness and the violation of psychological contract (Orvis et al., 2008).

\subsection{The crossover process}

The process whereby emotional states are transferred from one person to another is also known as crossover (Westman, 2001). Social psychological theoretical perspectives, such as role theory and emotional contagion theory, propose that stress outcomes are, at least to some extent, induced by social processes (Bakker et al., 2006). This specifically holds for crossover processes within teams because team-level crossover involves not only inter-individual transmission of stress and strain but also it applies to transmission of positive and negative feelings and attitudes in general. Workplace experiences of one employee may cross over and affect other employees (van Emmerik \& Peeters, 2009).

Westman et al. (2006) argue that there are three essential mechanisms responsible for crossover. The first mechanism concerns the direct transmission of well-being among partners. Strain in one partner produces an empathic reaction in the other that increases his or her level of strain. The second mechanism suggests that the relationship between partners' strain is spurious, since what appears to be a crossover effect is the result of common stressors experienced by both partners. For instance, if both partners are working intensively, they do not have much time to spend on their own joint, relaxing leisure activities. In addition, partners usually share similar family circumstances (e.g., family resources and stressors). Consequently, the fact that they share similar feelings can be due to shared context. Finally, Westman (2001) argues that crossover may be the result of an indirect interaction process. Specifically, she states that social support or undermining behaviors may mediate the crossover of one partner's strain to the other partner's strain. Indeed, it has been shown that social undermining (i.e. to express negative effect, convey negative evaluation or criticism, or hinder the attainment of instrumental goals) mediates the crossover of depression from one partner to the other (Westman et al., 2006).

Empirical studies have revealed the crossover of both positive and negative feelings between spouses. For instance, there is a positive bidirectional relationship between the partners' feelings of burnout, after controlling for job demands and job resources. In a study on working couples, Bakker et al. (2005) explained feelings of burnout and work engagement crossover between husbands and wives. In the context of work, Bakker et al. (2006) found positive relationships between team level burnout and individual team members experienced the engagement and the burnout and engagement. Finally, they explained a study that reported the crossover of daily work engagement between dyads of coworkers (ten Brummelhuis et al., 2011).

In the present study, we investigate the feelings of (diminished) engagement based on FWC crossover among co-workers. We will examine whether the crossover of engagement offers an explanation for the relationship between the employee's FWC and the co-worker's turnover intention. We predict that an employee experiencing more FWC will be less engaged at work, indicated by less vigor, 
dedication and absorption. As these work attitudes cross over to the co-worker, the co-worker's turnover intention will increase. This leads to the following set of hypotheses:

Hypothesis 1. Employee's FWC will be positively related to his (her) job engagement.

Hypothesis 2.Employee's job engagement will be positively related to his (her) co-worker job engagement.

Hypothesis 3. Employee's FWC will be positively related to co-worker turnover intention trough the crossover of (reduced) feelings of engagement.

Fig 2 shows the conceptual model in our study.

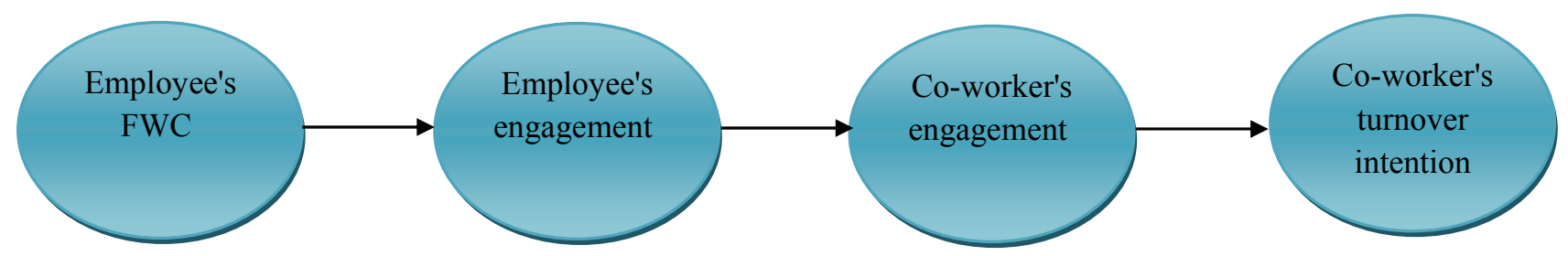

\section{Method}

Fig.2. The conceptual model

\subsection{Participants and procedure}

The data were collected during the period of time from April to July, 2011. 170 questionnaires were distributed at 15 branches in Mellat bank in Lorestan Province of Iran. Of 180 (90 dyads) questionnaires, 157 questionnaires were returned (response rate=87\%). Three questionnaires could not be used in the analyses since only one partner participated, leaving us with 154 questionnaires or 77 couples for data analyses. The demographic characteristics of these Participants are presented in Table 1.

\subsection{Measures}

We used two questionnaires in this study. Questionnaire A measured variable of employee's familyto-work conflict and employee's Job engagement. Questionnaire B measured variable of co-worker's Job engagement and co-worker's turnover intention.

\subsection{Family-to-work conflict}

To measure family-to-work conflict, we used scales developed by Carlson et al. (2000). Each scale consists of three items and measures one of the three dimensions of work-family conflict, that is, time-based WFC, strain-based WFC, and behavior-based WFC. Items were scored on a 5-point rating scale ranging from 1, 'strongly agree', to 5, 'strongly disagree'.

\subsection{Work engagement}

Engagement was measured with the 13-item UWES Schaufeli et al. (2000), which includes three subscales: Vigor (VI: 4 items), Dedication (DE:4 items), and Absorption (AB:5 items). Items were scored on a 5-point rating scale ranging from 1, 'strongly agree', to 5, 'strongly disagree'.

\subsection{Turnover intention}

To measure turnover intention, we used a modified version of the five-item-scale developed by Obruba (2001). Items were scored on a 5-point rating scale ranging from 1, 'strongly agree', to 5, 'strongly disagree'. 
Table 1

Demographic characteristics of Participants $(\mathrm{N}=77$ couples $)$

\begin{tabular}{|c|c|c|c|}
\hline \multicolumn{2}{|l|}{ Characteristic } & Employee (\%) & Co-worker $(\%)$ \\
\hline \multirow{2}{*}{ Gender } & male & 83.1 & 76.6 \\
\hline & female & 16.9 & 23.4 \\
\hline \multirow{4}{*}{ Age (years) } & $\leq 30$ & 36.4 & 24.7 \\
\hline & $31-40$ & 53.2 & 67.5 \\
\hline & $41-50$ & 9.1 & 7.8 \\
\hline & $\geq 51$ & 1.3 & - \\
\hline \multirow{2}{*}{ Marriage state } & Single & 18.2 & 11.7 \\
\hline & Married & 81.8 & 88.3 \\
\hline \multirow{6}{*}{ Education } & Below Diploma & 16.9 & 19.5 \\
\hline & associate of art & 16.9 & 20.8 \\
\hline & bachelor & 49.4 & 49.4 \\
\hline & MA & 10.4 & 10.4 \\
\hline & P.H.D & 1.3 & - \\
\hline & Missing value & 5.2 & - \\
\hline \multirow{5}{*}{ Number of dependent children } & Without children & 39 & 36.4 \\
\hline & 1 & 23.4 & 18.2 \\
\hline & 2 & 20.8 & 16.9 \\
\hline & $\geq 3$ & 16.9 & 23.4 \\
\hline & Missing value & - & 5.2 \\
\hline \multirow{5}{*}{ Number of dependent elderly } & Without elderly & 75.3 & 71.4 \\
\hline & 1 & 14.3 & 22.1 \\
\hline & 2 & 3.9 & - \\
\hline & $\geq 3$ & 1.3 & 2.6 \\
\hline & Missing value & 5.2 & 3.9 \\
\hline \multirow{4}{*}{ Work experience (years) } & $<5$ & 33.8 & 27.3 \\
\hline & $5-10$ & 5.2 & 39 \\
\hline & $11-20$ & 44.2 & 24.7 \\
\hline & $>20$ & 16.9 & 9.1 \\
\hline
\end{tabular}

\subsection{Reliability and validity analyses}

The reliability of data collected was measured using Cranach's alpha coefficient. The reliability test was conducted to check for inter-item correlation in each of variables in the questionnaire. Table 2 shows the Cranach's alpha coefficient for all the variables in the questionnaire obtained. The value of at least 0.70 is the basis of reliability for Cronbach alpha coefficient (Cronbach, 1951). All responses collected had passed the reliability test. Meanwhile, for survey validity of questionnaires, we used content validity and construct validity. Content validity refers to the fitness of the contents of the measurement tool.

The verification of content validity in social sciences depends on the professional knowledge of researchers. It is also possible to identify appropriate and relevant measurements from literature or employ the assistance of experts to determine the fitness of the contents, to enhance content validity, and to ensure questionnaire effectiveness. The development of measurement tools in this paper is based on generalization of literature reviews. All the sources are referenced in relevant empirical literature. The questions are modified after interviews with experts. Therefore, the questionnaire in this paper should carry a certain degree of content validity. 
Table 2

Summary of questionnaires, variables and dimensions reliability

\begin{tabular}{|c|c|c|c|c|c|}
\hline questionnaire & Cranach's $\alpha$ & variable & Cranach's $\alpha$ & dimension & Cranach's $\alpha$ \\
\hline \multirow{6}{*}{ A (employee) } & \multirow{6}{*}{0.819} & \multirow{3}{*}{ WFC } & \multirow{3}{*}{0.87} & time-based WFC & 0.906 \\
\hline & & & & strain-based WFC & 0.724 \\
\hline & & & & behavior-based WFC & 0.73 \\
\hline & & \multirow{3}{*}{ Job engagement } & \multirow{3}{*}{0.757} & VI & 0.829 \\
\hline & & & & DE & 0.733 \\
\hline & & & & $\mathrm{AB}$ & 0.712 \\
\hline \multirow{4}{*}{$\begin{array}{l}\text { B } \\
\text { (co-worker) }\end{array}$} & \multirow{4}{*}{0.836} & \multirow{3}{*}{ Job engagement } & \multirow{3}{*}{0.795} & VI & 0.818 \\
\hline & & & & DE & 0.89 \\
\hline & & & & $\mathrm{AB}$ & .731 \\
\hline & & Turnover intention & 0.843 & - & - \\
\hline
\end{tabular}

In our study, some items of the questionnaires are eliminated. For the sake of construct validity, we used from Kaiser-Meyer Olkin measure of sampling adequacy (KMO) and Bartlet's Test of Sphericity. Table 3 and Table 4 show the KMO and Bartlet's Test of Sphericity for questionnaires A and $\mathrm{B}$.

Table 3

Result of KMO and Bartlet's Test of Sphericity for questionnaires A (employee)

\begin{tabular}{llllllll}
\hline & & $\begin{array}{l}\text { time-based } \\
\text { WFC }\end{array}$ & $\begin{array}{l}\text { strain-based } \\
\text { WFC }\end{array}$ & $\begin{array}{l}\text { behavior- } \\
\text { based WFC }\end{array}$ & VI & \multirow{2}{*}{ DE } & \multirow{2}{*}{ AB } \\
\hline KMO & & 0.733 & 0.786 & 0.622 & 0.725 & 0.666 & 0.765 \\
\hline \multirow{2}{*}{$\begin{array}{l}\text { Bartlett's Test } \\
\text { of Sphericity }\end{array}$} & Chi-Square & 153.47 & 165.13 & 48.10 & 127.92 & 43.116 & 143.12 \\
& Df & 3 & 3 & 3 & 6 & 3 & 3 \\
& Sig. & 0.000 & 0.000 & 0.043 & 0.024 & 0.033 & 0.000 \\
\hline
\end{tabular}

Table 4

Result of KMO and Bartlet's Test of Sphericity for questionnaires B (co-worker)

\begin{tabular}{llllll}
\hline \multirow{2}{*}{ KMO } & & VI & DE & AB & Turnover intention \\
\multirow{2}{*}{$\begin{array}{l}\text { Bartlett's Test } \\
\text { of Sphericity }\end{array}$} & Approx. Chi-Square & 0.75 & 0.639 & 0.764 & 0.77 \\
& Df & 6 & 82.94 & 131.53 & 298.38 \\
& Sig. & 0.000 & 3 & 3 & 10 \\
\hline
\end{tabular}

Since KMO $>0.6$, we can conclude that the sample size for factor analysis is suitable. In addition, sig of Bartlet's Test of Sphericity is under $0.5(\mathrm{sig}<0.5)$, which means that the structure of factor model is also suitable.

\subsection{Strategy of analysis}

In order to test all four hypotheses simultaneously, structural equation modeling (SEM) techniques were employed using the SMART PLS software package. The result of the models was assessed with the Goodness of Ft Index (GFI), the Comparative-Fit-Index (CFI), Tucker-Lewis Index (TLI) and the Root Mean Square Error of Approximation (RMSEA). The indexes of goodness show that model is fit goodness (Table 5). All items had significant loadings on the intended factors.

\section{Table 5}

The indexes of model goodness

\begin{tabular}{lcc}
\hline Fit indicator & Validation value & Result \\
\hline GFI & 0.91 & Compliant \\
CFI & 0.89 & Compliant \\
TLI & 0.86 & Compliant \\
RMSEA & 0.08 & Compliant \\
\hline
\end{tabular}




\subsection{Hypothesis testing}

Fig. 3 (the conceptual model in state estimate), Fig. 4(the conceptual model in state significant) and Table 6 depict the structural model. The model includes pathways from employee FWC to co-worker turnover intention via employee engagement and co-worker engagement. The latent variables representing engagement had three indicators (the sub-dimensions). The null hypothesis, which states that $x$ does not have an indirect effect on $y$ via $m$, is confirmed when the entire confidence interval lies above or below zero.

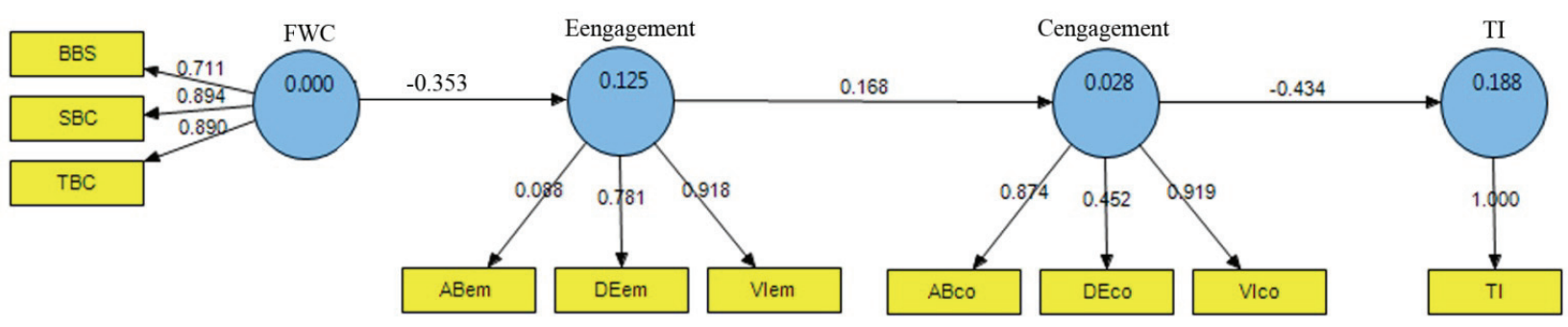

Fig.3. The conceptual model in state estimate

Note: $\mathrm{N}=154$. E refers to employee; $\mathrm{C}$ refers to co-worker, TI to turnover intention

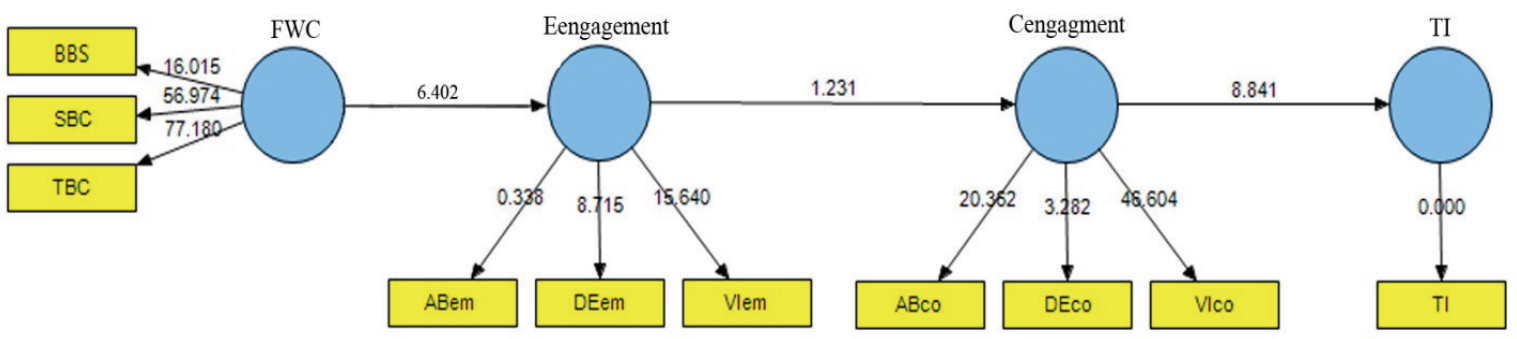

Fig.4. The conceptual model in state significant (t-value)

Note: $\mathrm{N}=154$. E refers to employee; $\mathrm{C}$ refers to co-worker, TI to turnover intention

Table 6

The result Path Analysis

\begin{tabular}{lcccl}
\hline Indirect effect $\mathrm{x} \rightarrow \mathrm{m} \rightarrow \mathrm{y}$ & Path coefficient $(\beta)$ & correlation coefficient & $\mathrm{t}$-value & result \\
\hline $\mathrm{FWC} \rightarrow$ Eengagement & $0.353-$ & $0.353-$ & 6.402 & Confirm \\
Eengagement $\rightarrow$ Cengagement & 0.168 & 0.168 & 1.231 & Confirm \\
Cengagement $\rightarrow$ turnover intention & $0.434-$ & $0.434-$ & 8.841 & Confirm \\
\hline Eengagement $\rightarrow$ turnover intention & $-0.073^{*}$ & - & - & Confirm \\
\hline FWC $\rightarrow$ Eengagement $\rightarrow$ Cengagement & $0.026^{* *}$ & - & - & Reject \\
\hline
\end{tabular}

$* 0.168 \times-0.434=0.026$

$* *-0.353 \times 0.168 \times-0.434=0.026$

Fig. 3, 4 and Table 6 show that Employee FWC was negatively related to employee engagement ($0.353)$. We found a considerable crossover effect of engagement between the employee and the coworker ( $\beta=0.168$ ). Employee engagement was substantially related to co-worker turnover intention $(-0.073)$. Employee FWC is not related to co-worker turnover intention via the level of engagement experienced by the employee and the co-worker (0.026). 


\section{Conclusions}

In this paper, we have performed an empirical study for the relationship between family-to-work conflict and co-workers' turnover intention. The proposed model of this paper selected employees of a publically Iranian company called Mellat Bank located in province of Lorestan, Iran. Based on the results of this study, Employee's FWC was negatively related to his (her) job engagement and employee's job engagement was positively related to his (her) co-worker job engagement. In addition, employee's engagement was negatively associated with co-worker turnover intention and employee's FWC was not positively related to co-worker turnover intention trough the crossover of (reduced) feelings of engagement. When the employee experienced FWC, their job engagement was reduced. We have concluded that family-to-work effects do not only occur within individual employees, but these effects may also cross over and impact co-workers. According to our study, the crossover of job engagement between employees (employee and co-worker) is possible but there is no reason for the crossover of employee's FWC and co-worker.

Our findings suggest that FWC is associated with engagement at work and while employees engage at their work, likewise co-workers engage at their work. In addition, while employees reduced engagement at their work, intention to turnover or change of their job has been increased.

\section{Acknowledgment}

The research study was financially assisted by a grant dedicated by Allameh Tabataba'i University and the authors would like to thank their efforts for their contributions. The authors are also grateful for constructive comments on earlier version of this work.

\section{References}

Bakker, A. B., Xanthopoulou, D., Demerouti, E., \& Schaufeli, W.B. (2009). Crossover of burnout and engagement in work teams. Work \& Occupations, 33, 464-489.

Bakker, A.B., Van Emmerik, I.J.H., \& Euwema, M.C. (2006). Crossover of burnout and engagement in work teams. Work and Occupations, 33, 464-89.

Burke, R.J., \& El-Kot, G. (2010). Work engagement among managers and professionals in Egypt. Potential antecedents and consequences. African Journal of Economic and Management Studies, 1, 42-60.

Carlson, D. S., Kacmar, K. M., \& Williams, K. J. (2000). Construction and initial validation of a multi dimensional measure of work-family conflict. Journal of Vocational Behavior, 56, 249-276.

Cronbach, L. J. (1951). Coefficient alpha and the internal structure of tests. Psychometrika, 16(3), 297-334.

Farkas, A.J., \& Tetrick, L.E. (1989). A three-wave longitudinal analysis of the causal ordering ofsatisfaction and commitment on turnover decisions. Human Resource Management, 74, 855-68.

Harrison, D., Newman, D., \& Roth, P. (2006). How important are jobattitudes? Metal-analytic comparisons of integrative behavioraloutcomes and time sequences. Academy of Management Journal, 49(2), 305-325.

Hyun, J. K., Kang, H. S., \& Nancy, S. (2009). Burnout and engagement: A comparative analysis using the Big Five personality dimensions. International Journal of Hospitality Management , 28, 96-104.

Lacity, M. C., Iyer, V. V., \& Rudramuniyaiah, P. S. (2008). Turnover intentions of Indian IS professionals. Information Systems Frontiers, 10, 225-241.

Liu, J.Y., \& Low, S.P. (2009). Developing an organizational learning-based model for risk management in Chinese construction firms: A research agenda. Disaster Prevention and Management, 18(2), 170 -186. 
Matthewsa, R.A., Booth, S.M., Taylor, C.F., \& Martin, T. (2011). A qualitative examination of the work-family interface: Parents of children with autism spectrum disorder. Journal of Vocational Behavior, doi:10.1016/j.jvb.2011.04.010.

Namasivayam, K., \& Zhao, X. (2007). An investigation of the moderating effects of organizational commitment on the relationships between work-family conflict and job satisfaction among hospitality employees in India. Tourism Management, 28, 1212-1223.

Orvis, K.A., Dudley, N.M., \& Cortina, J.M. (2008). Conscientiousness and reactions to psychological contract breach: a longitudinal field study. Journal of Applied Psychology, 93, 1183-93.

Schaufeli, W.B., Salanova, M., González-Romá, V., \& Bakker, A. B. (2000). The measurement of burnout andengagement: A confirmative analytic approach. Journal of Happiness Studies, 5, 464481.

Schaufeli, W.B., \& Bakker, A. (2004). Job demands, job resources, and their relationship. Journal of Organizational Behavior, 25 , 293-315.

Shih, H. A., \& Susanto, E. (2011). Is innovative behavior really good for the firm? Innovative work behavior, conflict with coworkers and turnover intention: moderating roles of perceived distributive fairness. International Journal of Conflict Management , 22, 111-130.

ten Brummelhuis, L. L., Bakker, A. B., \& Euwema, M. C. (2010). Is family-to-work interference related to co-workers' work outcomes? Journal of Vocational Behavior, 77, 461-469.

van Daalen, G., Willemsen, T. M., \& Sanders, K. (2006). Reducing work-family conflict through different sources of social support. Journal of Vocational Behavior, 69, 462-476.

van Emmerik, I.J.H., \& Peeters, M.C.W. (2009). Crossover specificity of team-level work-family conflict to individual-level work-family conflict. Journal of Managerial Psychology, 24(3), 254268.

Westman, M. (2001). Stress and strain cross over. Human Relations, 54, 717-751.

Westman, M., Etzion, D., \& Danon, E. (2006). Job insecurity and crossover of burnout in married couples. Journal of Organizational Behavior, 22, 467-481. 